\title{
Laser scan-based structural assessment of wrought iron bridges: Guinness Bridge, Ireland
}

1 Nora Gyetvai BSC, ME

Former Master's Student, School of Civil Engineering, University College Dublin, Dublin, Ireland

2 Linh Truong-Hong PhD

Research Scientist, Urban Modelling Group, School of Civil

Engineering, University College Dublin, Dublin, Ireland (Orcid:0000-0003-2126-6409)
3 Debra F. Laefer PhD

Professor of Urban Informatics and Director of Citizen Science, Center for Urban Science and Progress, New York University, New York, NY, USA; Adjunct Professor, Urban Modelling Group, School of Civil Engineering, University College Dublin, Dublin, Ireland (corresponding author: debra.laefer@nyu.edu) (Orcid:0000-0001-5134-5322)
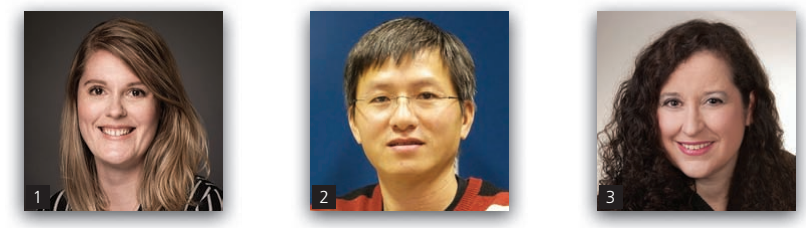

This paper introduces a workflow to create the geometric documents for conducting the finite-element-based structural assessment of wrought iron bridges using laser scanning data as the input dataset. First, a methodology for identifying actual cross-sections of the bridge components based on a point cloud obtained from a terrestrial laser scanner (TLS) is presented. Next, a non-parametric regression kernel density estimation is employed to determine overall bridge dimensions to populate a computational model by projecting the position of the web and/ or flange surface of the cross-section (appearing as local maximum peaks of a probability density shape). The process is demonstrated with respect to the previously undocumented Guinness Bridge in Dublin, Ireland, to determine the bridge's behaviour. The successful generation of this model proves that TLS can surpass other common techniques (e.g. unmanned aerial vehicle-based images) for acquiring the bridge geometry necessary for reconstructing accurate member cross-sections and overall bridge dimensions, regarding the quantity and quality of the data points, and timing. The finite-element analysis showed that the bridge currently satisfies both strength and serviceability requirements under self-weight but would be unlikely to support a new slab and a modern pedestrian load level as per current code requirements for reopening the bridge.

\section{Notation}

$H \quad$ distance between the local maximum peaks (LMPs) of the probability density shape (PDS) derived from the bottom and top chords

$h \quad$ bridge height

L bridge length

$M \quad$ maximum bending moments

$P \quad$ maximum axial forces

$P_{\mathrm{DL}} \quad$ applied dead load

$P_{\mathrm{LL}} \quad$ applied live load

$S_{11} \quad$ principle stress

$\Delta_{\mathrm{B} 1} \quad$ distance between a gravity centre of the bottom chord to the LMP of the PDS of the lower parts of the bottom chord

$\Delta_{\mathrm{B} 2} \quad$ distance between a gravity centre of the bottom chord to the LMP of the PDS of the upper parts of the bottom chord

$\Delta_{\mathrm{T} 1} \quad$ distance between a gravity centre of the top chord to the LMP of the PDS of the lower parts of the top chord

$\Delta_{\mathrm{T} 2} \quad$ distance between a gravity centre of the top chord to the LMP of the PDS of the upper parts of the top chord

\section{Introduction}

The Guinness Bridge in Dublin, Ireland, represents an invaluable part of the country's largely disregarded industrial heritage and dates back to the early 1900s. The bridge was the first of its kind in Ireland to carry hydroelectric power and services across the nearby valley to the Farmleigh estate. The bridge has not been used since the 1960s, and no maintenance records were found despite state ownership beginning in 1999. The structure is in an extremely deteriorated state due to half a century of neglect and was nominated to the World Monument Fund's 'Most at Risk' list in 2012. At the time of the nomination, the structure's state and the exact extent of deterioration were both unknown, which precluded the development of a restoration plan and affiliated fundraising. Without a preliminary structural assessment, fundraising and further assessment were stymied. In response, faculty and students at the University College Dublin undertook an evaluation of this late nineteenth-century wrought iron structure as part of an academic programme. As such, the following serves both as a case history and as a framework for the assessment of a historic wrought iron bridge using terrestrial laser scanning (TLS) data. 
Visual inspection is a predominant method used in bridge assessment, because the method has the advantage of being simple. It is, however, subjective and highly dependent on an inspector's experience, particularly when working in adverse conditions (e.g. weather and access) (Phares et al., 2004; Zhu et al., 2010). For structures with highly restrictive site access and limited budgets, effective visual inspection with physical inspectors cannot be done. In contrast, TLS is a non-contact measurement method that offers an alternative by acquiring three-dimensional (3D) topographic data on visible surfaces of structural members with millimetre accuracy. Once acquired, TLS data can be processed to generate a permanent record of a structure's status or to report structural deficiencies. This paper describes a methodology developed for the geometric documentation and safety evaluation of this bridge, which could be adapted as a template for other historic metal bridges.

\section{Background}

According to the International Council on Monuments and Sites Charter (Icomos, 2003), heritage lies in both the appearance and the integrity of all visible and hidden structural components, as they represent the building technology of a certain time. However, engineers must assess the safety of heritage structures by considering the nature and effects of these structural components (Icomos, 2003). Ultimately, the structural evaluation of a metal bridge can be done through direct testing, modelling or a combination of both.

TLS has been emerging as a non-contact measurement approach to acquire 3D topographic data of objects quickly and accurately. For example, Armesto-González et al. (2010) presented a methodology using a combination of TLS and digital image processing to detect damage to the stone ruins of Santo Domingo. In another application, Al-Neshawy et al. (2010) used a Faro LS 880HE80 scanner to acquire geometric data of a wall to detect the bowing of marble cladding. Other notable case studies employing TLS in heritage building assessment include the works of Camarda et al. (2010), who surveyed the Olympic theatre in Vicenza using photogrammetry and TLS. To obtain a 3D model capturing architectural details and areas with high surface curvatures, a 3D triangulated mesh model of the theatre was created using the Geomagic software, which is as an input model for finite-element method (FEM) analysis. Similarly, Castellazzi et al. (2015) developed the procedure Cloud2Fem, which used voxels to represent a point cloud of a structure in order to semiautomatically generate a FEM model of a historic monument building from TLS data based on the earlier introduction of this approach by others (Hinks et al., 2013). More generally, Olsen et al. (2010) proposed a framework for the use of TLS to model existing structures and capture deflections, while extending its applicability to damage and volumetric change analysis. Additionally, the authors also addressed parallax and mixed pixel errors that occurred around the edges of the specimen in close range data capture and which required further data filtering.

Moreover, TLS has also been used widely for heritage structure documentation and assessment (e.g. Armesto-González et al.,
2010). To such ends, TLS data have been used for geometric reconstruction, as well as the examination of surface damage, deflections and degradation. In an extensive study of documentation techniques for heritage bridges, Fereshteh (2012) concluded that TLS is ideal where the rapid collection of undocumented geometry is needed and/or where the presence of an inspector on the structure itself may pose a safety hazard. That can be seen through the work of Heath and Miller (2014) using TLS to support the assessment of the Iron Bridge in Shropshire, UK. In that case, 3D topographic data of the bridge were acquired through 162 TLS scans with a Faro Focus and 47 from a Riegl VZ400. With those data, the authors employed modelling tools from Rhinoceros to generate a 3D surface model of the main span. Afterwards, Miller (2015) converted the surface model to a solid model for finite-element analysis including the structure's defects (either deleting elements or reducing the stiffness of selected elements). While this helpful example provides some guidance for bridge assessment, generating meaningful surface models of metal bridges from point clouds remains a challenge, particularly with respect to cross-section component identification. Generally, the readers are referred to the study by Truong-Hong and Laefer (2014) for a further discussion on using TLS for bridges, which can be used for deformation measurement, for example, to determine a rate of mass loss or detect bridge components' cracking. To understand these issues better and to present a semi-automated method for TLS data processing, the following sections of this paper present a case study of the Guinness Bridge, wherein TLS was used to collect geometric data of the metal bridge to determine the cross-sections of the structural members for structural assessment.

\section{Methodology}

This study aimed to demonstrate how TLS can be used to collect rapidly and inexpensively sufficient data to create a permanent record of a previously undocumented bridge in its current condition without imperilling the site engineers. The project had the further goals of using TLS data to create a geometric model for structural analysis for a safety evaluation. However, since the extensive damage of the bridge was apparent from even the most cursory visual inspection, there was concern that the bridge was possibly beyond immediate serviceability. Thus, the evaluation was to be based on a structural analysis conducted on both the strength and the serviceability requirements for immediate and long-term scenarios. Visible damage was modelled by assuming reduced stiffness or the removal of structural components. The methodology of this investigation involved the field documentation of the Guinness Bridge, followed by the automatic estimation of primary dimensions of the bridge, and then followed by an estimate of actual cross-sections of the components to create a numerical model with undamaged structural components. Finally, an element-by-element assessment of the structural components under various load scenarios was conducted.

As part of this process, cross-sections of the bridge components were manually identified based on the point cloud of the cross- 
section and a library section. The actual section of the component was based on the section in the library that best matched the point cloud in terms of height, width and cross-sectional area. Notably, no previous records of the geometry and/or performance of the Guinness Bridge were known to exist; therefore, the assessment detailed in this report was based solely on this study using known sections from other projects, as will be described below.

\subsection{Field work and scanning process}

The scan of the Guinness Bridge was conducted using a Leica ScanStation P20, which can acquire up to a million data points per second with an accuracy of $5 \mathrm{~mm}$ within the measurement range of $50 \mathrm{~m}$ (for detailed technical specifications of the scanner, see Truong-Hong et al., 2014). A visual survey of the site assisted in the identification of suitable access routes to the structure, selection of viable scan station locations and positions (to maximise data capture) and positional determination of obstructive vegetation.

Because of the absence of a riverbank on the south side, no public access was available there. On the north side, significant trees also limited the access. Thus, only two scan positions could be set up - both from the north (Figure 1). Station locations were chosen to maximise a clear line of sight towards the structural members of the bridge and to minimise the angle of incidence. As part of the process, a pair of high-definition black-and-white 6 " $(15 \cdot 24 \mathrm{~cm})$ targets were positioned to collect reference data for registering the point clouds from the two scan stations. At each scan station, two levels of scanning were conducted: an overall scan and a detailed scan. The first had a sampling step of $12.5 \mathrm{~mm}$ for overall geometrical data of bridge members. The second for recording detailed cross-sections had a $1.6 \mathrm{~mm}$ sampling step at the measurement range of $10 \mathrm{~m}$. Scanning at each position required around $30 \mathrm{~min}$ for data acquisition.

\subsection{Data processing}

Following data collection, the processing of the raw point cloud was undertaken to extract the required information for creating 3D solid models of the bridge for documentation and a subsequent numerical model. This was done using a combination of AutoCad with the plug-in CloudWorx (Leica Geosystems AG, 2016) for cross-section identification and novel algorithms developed by the authors for overall dimension estimation. After data acquisition,

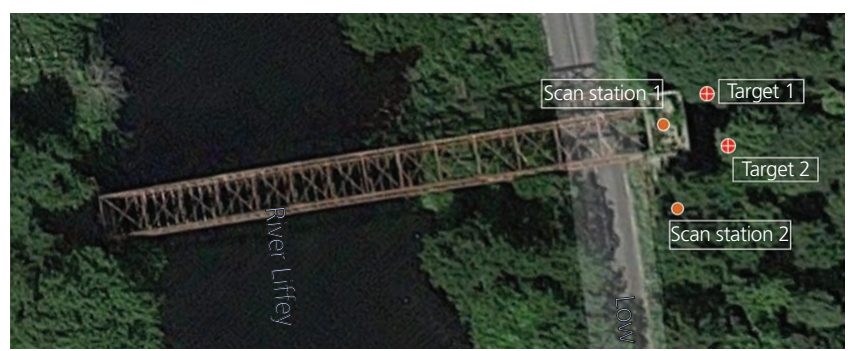

Figure 1. Positions of scan stations and targets the point clouds from multiple TLS scan stations were imported into Leica Cyclone V.9.1 (Leica Geosystems AG, 2014) for coregistration using the two common artificial targets. A total of 15.33 million points were collected, with 9.57 million of which describing the bridge (Figure 2). Following the coregistration of the two scans, irrelevant data points (e.g. points of the trees) were manually removed using the software's cropping tools.

To be able to assess the structure numerically, a 3D geometric model of the bridge was required. Obtaining this involved two main steps: (a) identifying the cross-section of each structural member from a point cloud and $(b)$ determining the overall dimensions of the bridge consisting of its total length, width and height, as well as the distance between individual deck beams and struts.

In step 1, an actual cross-section of a structural component was identified by comparing the section-based point cloud to a library of sections. The library was created from the Historical Structural Steelwork Handbook (Bates, 1991). As a formal standardisation of wrought iron sections had yet to exist fully within the industry, this use of steel sections may have contributed to small discrepancies; however, since no quantifiable documentation of the bridge existed, this proxy had to be used.

When exporting a point cloud from Leica Cyclone V.9.1 (Leica Geosystems AG, 2014) into AutoCad using the plug-in CloudWorx (Leica Geosystems AG, 2016), working with an entire point cloud is difficult because $(a)$ the AutoCad programme requires intensive hardware (i.e. Ram and graphics card) to handle and visualise a massive data point and (b) distinguishing individual components within the full point cloud is visually challenging. Additionally, the bridge's components are repetitive in nature. Thus, the point cloud of each structural component was imported into the AutoCad programme separately for identifying the cross-section, and the process was applied across all of the bridge's components individually. Notably, since the point cloud density is proportional to the offset distance, the structural component closest to the scanner (having the highest point density) was used for the initial identification of the repeated member's cross-section.

To obtain the actual cross-section of the structural elements, a local coordinate system was defined for the structure by defining a user coordinate system (UCS) in the AutoCad programme, where the $z$-axis was parallel to the longitudinal direction of the

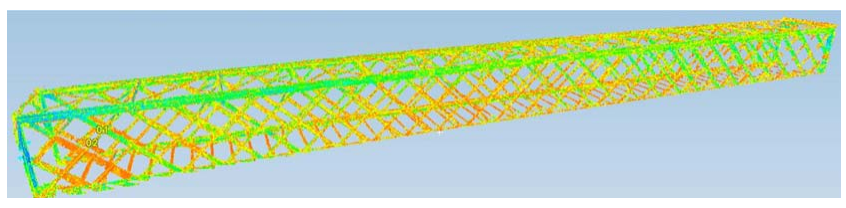

Figure 2. Point cloud of the Guinness Bridge after registration and removal of irrelevant points 
Engineering History and Heritage

Volume 171 Issue EH2
Laser scan-based structural assessment of wrought iron bridges: Guinness Bridge,

Ireland

Gyetvai, Truong-Hong and Laefer component and its cross-section lays on the $x-y$ plane. Following alignment, the point cloud of the cross-section of a given structural component was cropped using the 'Clipping' tool in Leica CloudWorx (Leica Geosystems AG, 2016). An iterative procedure for section identification was applied. The process is illustrated in Figures 3 and 4, being applied to the bottom and top chords, respectively. Photographs of the structural members further supported the identification of the components (Figures $3(\mathrm{a})$ and 4(a)).

After projecting the point cloud of the cross-section onto the $x-y$ plane, an outline of the section was first sketched manually using in-built AutoCad tools (Figures 3(b) and 4(b)). Using photographs as supplemental information, the individual components of each cross-section were identified. A possible section shape for each component was then estimated. This was necessary due to the highly complex composite geometry of the pieces. For example, the bottom and top chords were made from an $\mathrm{L}$ section and multiple plates (Figures 3(c) and 4(c)).
Next a cross-section from the section library with the closest dimensions to that of the point cloud was inserted into AutoCad and manually mapped onto the estimated section. Figures 3(d) and 4(d) depict the final cross-sections derived from the library for the bottom and top chords, respectively. The same process was then applied to the top chords, bottom chords, ties, sway bracing, lateral cross-bracing, lattice web elements, deck, arch, end posts and plate girders. Differences between the estimated crosssectional areas and the sections in the library are shown in Table 1 . The deviations ranged between 1.36 and $30.65 \%$, but most differed by less than $10 \%$.

Step 2 was an automatic procedure to estimate the primary dimensions of the bridge to create a numerical model appropriate for FEM analysis. The dimensions included the bridge's overall length, width and height, as well as the separation distances between the individual deck beams and the individual struts (Figure 5). The dimensions were reported as centre of gravity to centre of gravity of the elements, as opposed to the clearance. To

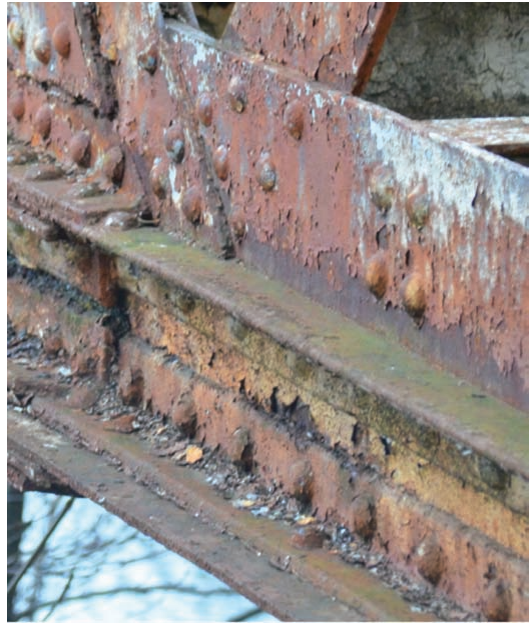

(a)

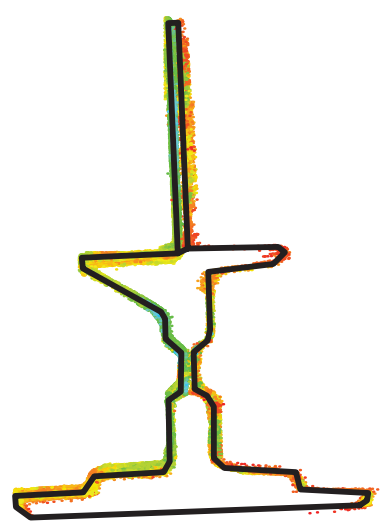

(b)

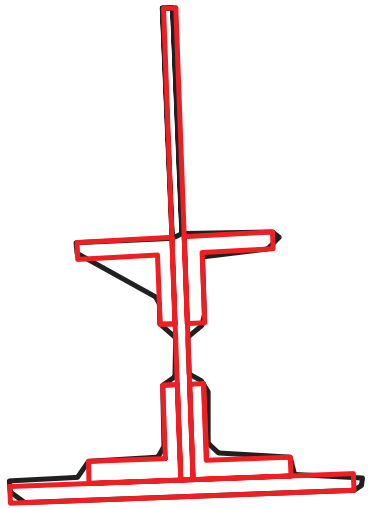

(c)

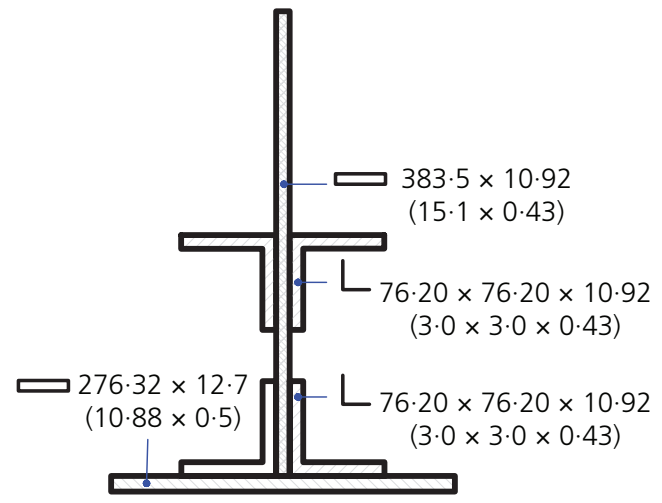

(d)

Figure 3. Evolution of point cloud to a final cross-section of the bottom chord (note: value in brackets is in imperial units). (a) Photograph of a bottom chord; (b) sketch of a cross-section outline based on a point cloud; (c) estimate of a cross-section based on the sketched section; (d) finalised cross-section based on a library entry 


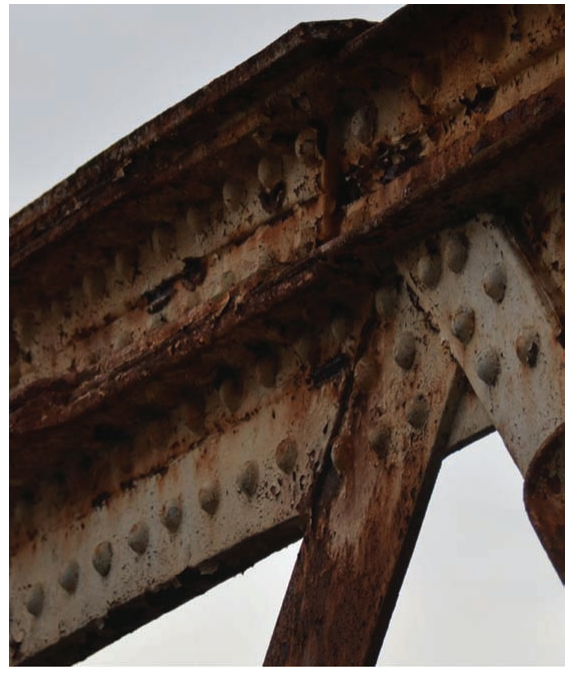

(a)

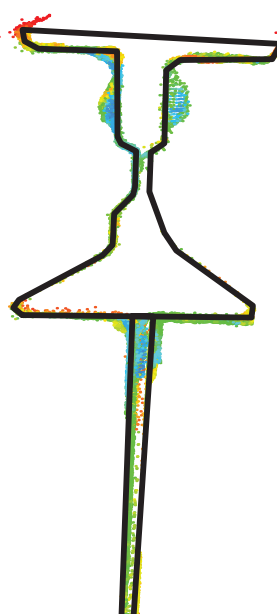

(b)

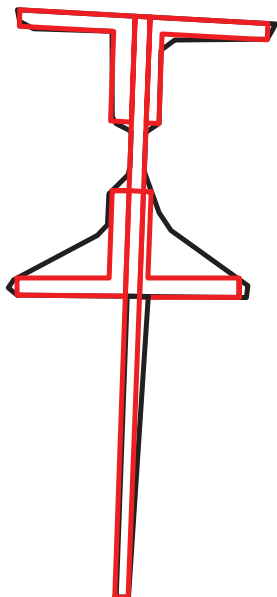

(c)

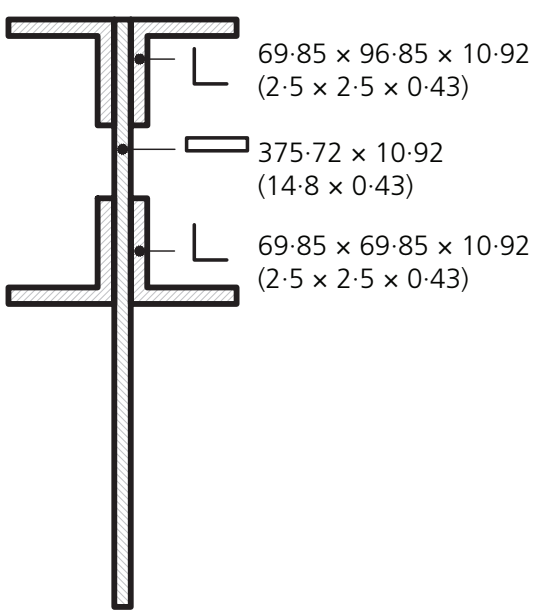

(d)

Figure 4. Evolution of point cloud to a final cross-section of the top chord (note: value in brackets is in imperial units). (a) Photograph of a bottom chord; (b) sketch of a cross-section outline based on a point cloud; (c) estimate of a cross-section based on the sketched section; (d) finalised cross-section based on a library entry

achieve these objectives, based on data point distributions, a statistical model was developed to estimate the position of the web and/or flange surface of the section, which was an important component for determining those dimensions. This was done using non-parametric regression, kernel density estimation (Laefer and Truong-Hong, 2017) to detect the primary surfaces (web and

Table 1. Summary of element cross-sections relating scanned and standard dimensions

\begin{tabular}{|c|c|c|c|c|}
\hline Element & Estimated cross-sectional area: mm$^{2}$ & Standard cross-sectional area: $\mathrm{mm}^{2}$ & Absolute error: $\mathrm{mm}^{2}$ & Relative error: \% \\
\hline Bottom chord & 14800 & 13800 & -1000 & $-7 \cdot 25$ \\
\hline Top chord & 9170 & 9700 & 530 & $5 \cdot 45$ \\
\hline Deck beam & 4230 & 4150 & -80 & -1.93 \\
\hline Arch & 2120 & 1940 & -180 & $-9 \cdot 28$ \\
\hline Tie & 2260 & 2420 & 160 & $6 \cdot 61$ \\
\hline Sway & 1050 & 930 & -120 & $-13 \cdot 27$ \\
\hline Lateral bracing & 520 & 480 & -40 & $-7 \cdot 64$ \\
\hline Double lattice & 2430 & 1860 & -570 & $-30 \cdot 65$ \\
\hline Single lattice & 3630 & 3680 & 50 & $1 \cdot 36$ \\
\hline End post & 3200 & 3070 & -130 & $-4 \cdot 23$ \\
\hline
\end{tabular}




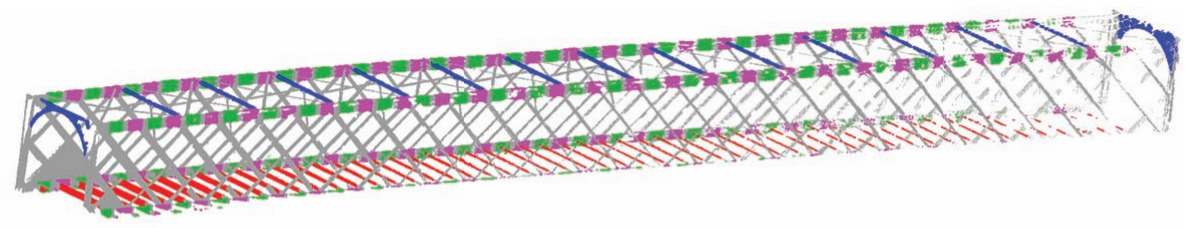

(a)

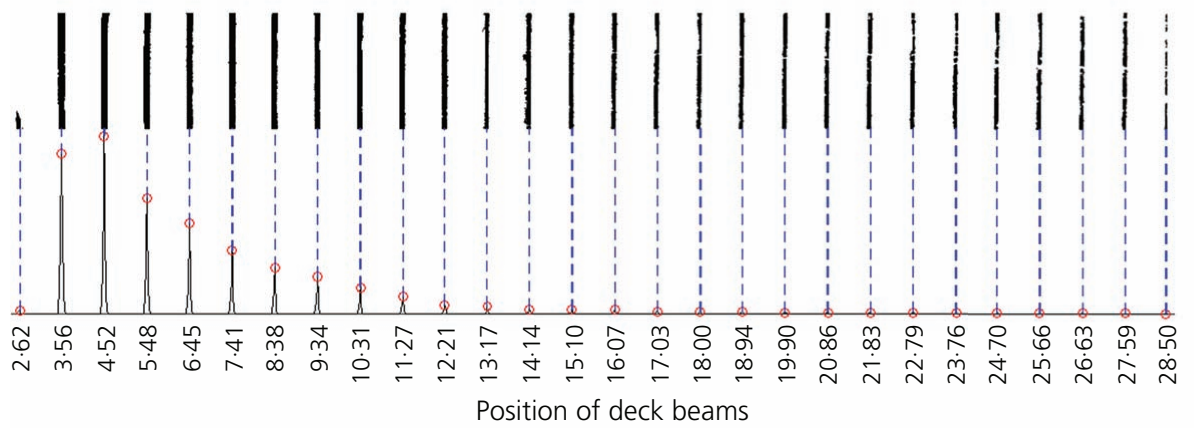

(b)

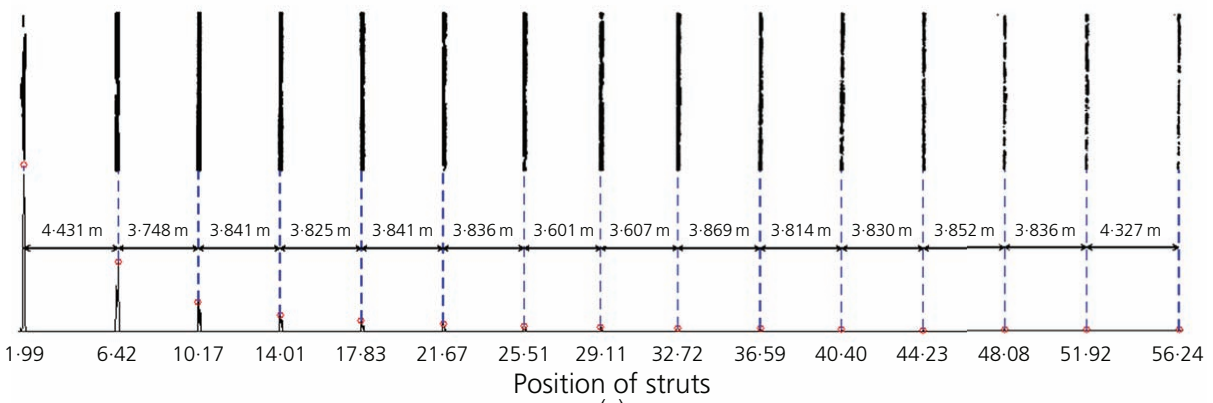

(c)
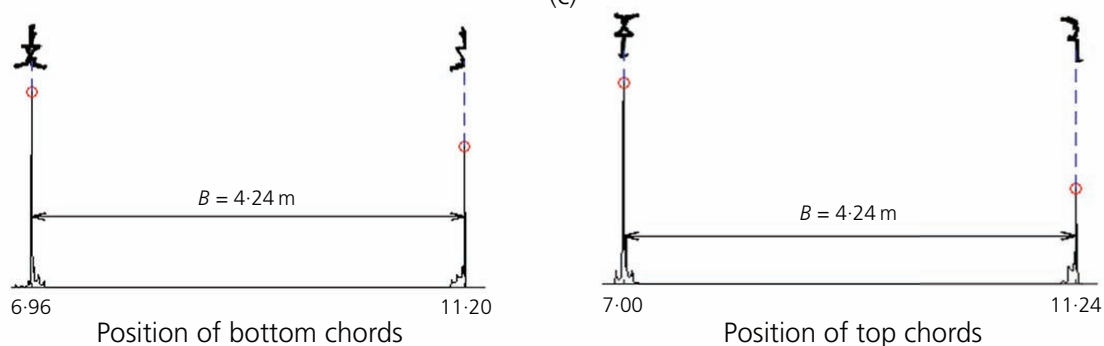

(d)

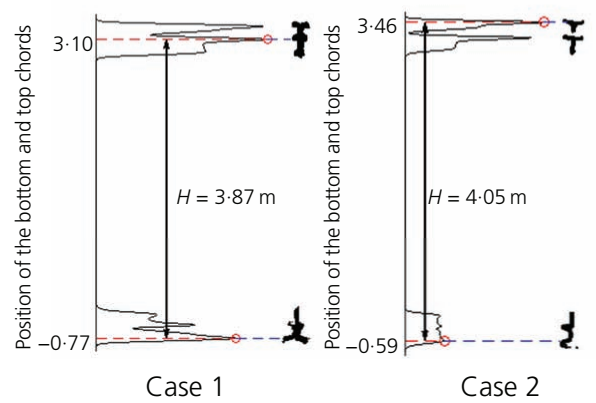

virtual scanner

Virtual
data points

Top chord

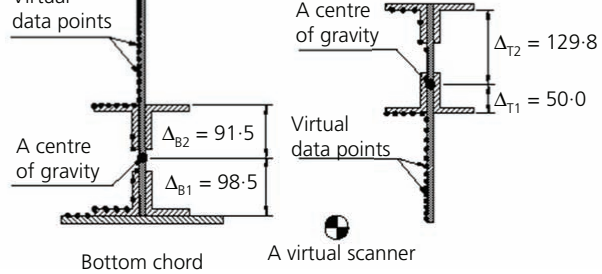

A distance between a centre of gravity to LMPs

(e)

Figure 5. A point cloud of segments for determining primary dimensions of the bridge based on LMPs of PDS from KE. (a) Point clouds of structural components used to estimate primary dimensions of the bridge for creating the computational model; (b) distances between deck beams (half of the bridge from the north side) estimated from the point clouds of the deck beam; (c) distances between struts estimated from a point cloud of struts; (d) bridge width predicted from the point cloud of pairs of bottom or top chords, a distance between the centre of gravity to the LMPs; (e) bridge height predicted from the point cloud of the bottom and top chords. Note: circles denote LMPs of PDS generated by kernel estimation 
flanges) of the structural member, which appeared as local maximum peaks (LMPs) of a probability density shape (PDS). The member dimensions were then derived from the positions of the LMPs. Details of the method for dimension estimation to create the 3D computational model are explained below.

The deck beam was extracted (Figure 5(a)) from the bridge point cloud (Figure 2). The PDS was then generated from the point cloud's $y$-coordinates using the empirically selected bandwidth of ten times the sampling step along the longitudinal direction. PDS results are shown in Figure 5(b). From the LMP positions describing the location of the deck beams, the distance between beams was determined to be $0.960 \mathrm{~m}$, with a standard deviation (std) of $0.026 \mathrm{~m}$. Notably, since the first deck beam was embedded into the rock face, the point cloud of this beam was not available, but the distance from the second deck beam to the end post was approximately $0.750 \mathrm{~m}$, as measured from the data points of the second deck beam and from one of the end posts. Measurement was done by way of an AutoCad plug-in tool with Leica CloudWorx (Leica Geosystems AG, 2016).

Similarly, the point clouds of the struts were also extracted (Figure 5(a)). In Figure 5(c), the LMPs of the PDS generated from the y-coordinates of the points demonstrated that the distance between the struts can be divided into three groups: $(a)$ the first bay of the north and south sides with an average distance of $4.379 \mathrm{~m}(\mathrm{std}=0.073 \mathrm{~m}) ;(b)$ a pair of bays at the middle with a distance of $3.604 \mathrm{~m}(\mathrm{std}=0.004 \mathrm{~m})$; and $(c)$ other elements with a distance of $3.830 \mathrm{~m}(\mathrm{std}=0.032 \mathrm{~m})$.

Based on the distances between the deck beams and between the struts above, the bridge length was calculated. The inner 55 deck beams had an average distance between them of $0.960 \mathrm{~m}$, while the outermost pairs of deck beams at each end were $0.750 \mathrm{~m}$ apart. Thus, the lower portion of the bridge was calculated to be approximately $54.30 \mathrm{~m}$ long. However, based on the number of struts and their offsets from each other (using an identical procedure), the upper portion of the bridge was only $54 \cdot 27 \mathrm{~m}$ long. Since the difference in bridge length was only $3 \mathrm{~cm}$, the disparity was not considered critical for the analysis, and the length generated based on the deck beams $(54.30 \mathrm{~m})$ was used to create the computational model, as it was closer to the scan data and, thus, considered to be more accurate.

To estimate the bridge width, the bottom and top chords were extracted separately (Figure 5(a)). The segment located between the two adjacent deck beams was automatically extracted based on the LMP of the PDS. From pairs of bottom (or top) chords, a PDS based on the $x$-coordinate of the data points was then generated to predict the locations of each web (Figure 5(e)). The distance between the webs was considered as the bridge width for the segment. The average bridge width was $4 \cdot 257 \mathrm{~m}(\mathrm{std}=0.036 \mathrm{~m})$.

Similarly, the point cloud of a segment involving the bottom and top chords on the same vertical truss plane was used to predict the bridge height. The PDS generated from the $z$-coordinate of the data points enabled the positional prediction of the flanges of the cross-section of the chords (Figure 5(e)). Subsequently, the distance between the flanges of the cross-sections of the bottom and top chords could be determined. However, since the bridge height $(h)$ from the numerical model was the distance between the gravity centres of the bottom and top chords, the distance in Figure 6(e) had to be adjusted by the distance from the gravity centre of the cross-section to the flanges as the LMPs. For example, for case 1 , the amount of $0.0485 \mathrm{~m}\left(h=H-\Delta_{\mathrm{B} 1}+\Delta_{\mathrm{T} 1}\right)$ had to be subtracted, while the distance in case 2 was $0.2283 \mathrm{~m}$ $\left(h=H-\Delta_{\mathrm{B} 1}-\Delta_{\mathrm{T} 2}\right.$ ) (Figure 5(e)). The resulting average bridge height was $3.709 \mathrm{~m}(\mathrm{std}=0.016 \mathrm{~m})$.

\subsection{Computational analysis}

A final 3D geometric model of the bridge, which also integrated a severe state of deterioration derived from a visual inspection (Truong-Hong and Laefer, 2015a, 2015b), is shown in Figure 6. Thus, an FEM assessment was performed to examine the strength and serviceability requirements of the bridge under different scenarios. Using the overall bridge dimensions and element crosssections acquired in the previous section, an as-designed model of the bridge was created in Sap2000 V.17 (CSI, 2014), which initially assumed no deterioration. The bridge components including bottom and top chords, deck beams, lattice, sway bracing, arch and end posts

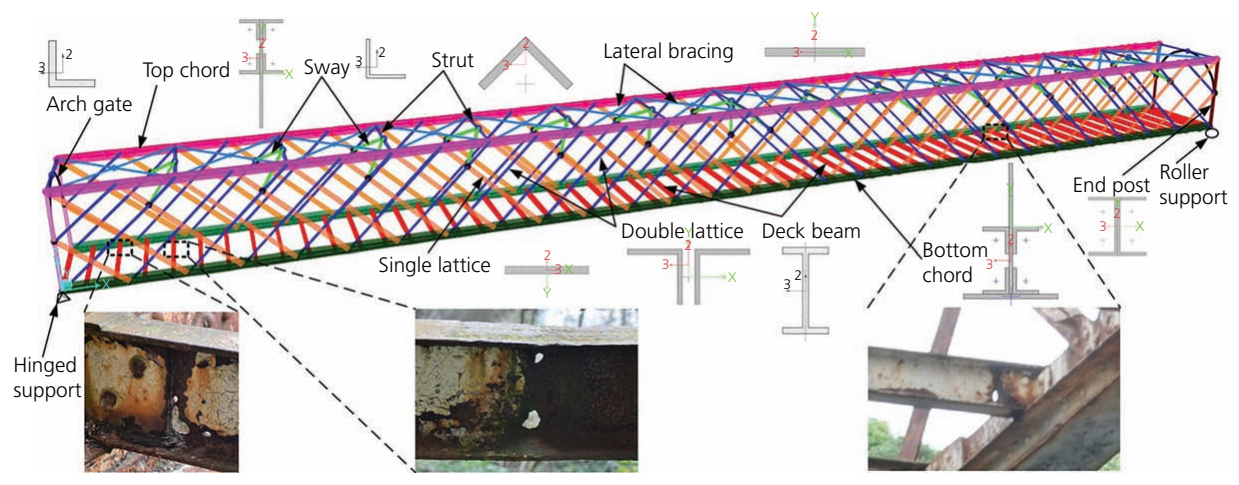

Figure 6. FEM model of Guinness Bridge 
Engineering History and Heritage

Volume 171 Issue EH2
Laser scan-based structural assessment of wrought iron bridges: Guinness Bridge,

Ireland

Gyetvai, Truong-Hong and Laefer were modelled by frame elements. However, deck beams, lattice, sway bracing, arch and end posts (Figure 6) having rivet connections at the ends were modelled as truss elements, by releasing the bending moment at both ends and torsion moment at one end. Finally, since lateral bracing provides stability against lateral loads, it acts in tension only and was, thus, modelled with a cable element. The 'Section Designer' extension of Sap2000 V.17 was used to define composite, unique cross-sections of the structural components. In such cases, the program merged multiple, individual sections of the component into the single geometry. Hinged and roller supports were, respectively, applied for the boundary conditions of north and south abutments (Figure 6). Material properties specified in Table 2 were assigned to the bridge's elements.

The aims of the FEM analysis were to assess strength and service requirements of the bridge structure in its current condition and then to answer the question of whether a new deck slab could be rebuilt safely to serve the community for pedestrian usage. Although a visual inspection recorded extensive damage in the deck beams, including surface lose due to corrosion and deformation, those damages could not be fully documented under current access limitations (Figure 6). Notably, connections between some deck beams and the bottom chord were welded, thereby showing some post-construction maintenance. As such, the present condition was analysed under four scenarios: case 1: the asdesigned bridge model without any damage; case 2: case 1 but with the stiffness of moment of inertia of all deck beams reduced by $50 \%$ to represent corrosion; case 3 : case 1 but with selected deck beams removed (Figure 7) - deck beam removal was based on assumed surface loss due to severe corrosion (derived from ground-based inspection images); and case 4: case 1 but with a new deck slab similar to the original (Figure $8(a)$ ). For this case, a universal beams (UB) $127 \times 76 \times 13$ (British steel section) was assumed as a stringer for a $10 \mathrm{~cm}$ deep ash wood deck slab.

Table 2. Material properties of wrought iron

\begin{tabular}{lcl} 
Aspect & Wrought iron & \multicolumn{1}{c}{ Reference } \\
$\begin{array}{l}\text { Young modulus of } \\
\text { elasticity, } E: \mathrm{N} / \mathrm{mm}^{2}\end{array}$ & $1.99 \times 10^{5}$ & Friedman (2010) \\
$\begin{array}{l}\text { Poisson's ratio, } v \\
\text { Tensile strength, } \sigma_{\mathrm{t}}: \mathrm{N} / \mathrm{mm}^{2}\end{array}$ & 0.278 & Rattan (2011) \\
$\begin{array}{c}\text { Compressive strength, } \\
\sigma_{\mathrm{c}}: \mathrm{N} / \mathrm{mm}^{2}\end{array}$ & 81 & Bates (1991) \\
Mass density, $W: \mathrm{kg} / \mathrm{m}^{3}$ & 74 & Bates (1991) \\
& & Doran and \\
& & Cather (2013)
\end{tabular}

Since cases 1-3 had no slab, the bridge was subjected only to selfweight, which was defined by the cross-sectional area, the lengths of the structural members and a mass density. In case 4 , the bridge was subjected to both dead load (DL) and live load (LL). The dead load from the slab system (stringers and slab) was computed from the self-weight of the stringer at $13 \mathrm{~kg} / \mathrm{m}$ and ash wood, with a mass density by $710 \mathrm{~kg} / \mathrm{m}^{3}$. In addition, for LL, a modern pedestrian load of $4.3 \mathrm{kN} / \mathrm{m}^{2}$ equivalent to $90 \mathrm{psf}$ was selected according to the American Association of State Highway and Transportation Officials (AASHTO, 2012). The concentrated loads from the slab system transferred to the deck beam are shown in Figure 8(b). However, since the distances between the deck beams differ, the dead load $\left(P_{\mathrm{DL}}\right)$ and live load $\left(P_{\mathrm{LL}}\right)$ were applied to the deck beams in accordance with their spacings $(0.3$ and $1.4 \mathrm{kN}$ for the first and last beam, 0.7 and $3.5 \mathrm{kN}$ for the second and the penultimate deck beams, and 0.8 and $4.1 \mathrm{kN}$ for others) (Figure $8(\mathrm{~b})$ ). Finally, load combinations under strength I (STR1) and service I (SER1) according to AASHTO (2012) were used in this assessment. For STR1, the load factors for DL and LL were, respectively, 1.25 and $1 \cdot 75$, while in SER1, all load factors were $1 \cdot 0$.

\section{Results}

Results of the major internal forces involving axial force and bending moment under STR1 from cases 1-4 are depicted in Figures 9 and 10 for the bottom and top chords, while the summary of the maximum and minimum of load $(P)$ and bending moments $(M)$ are

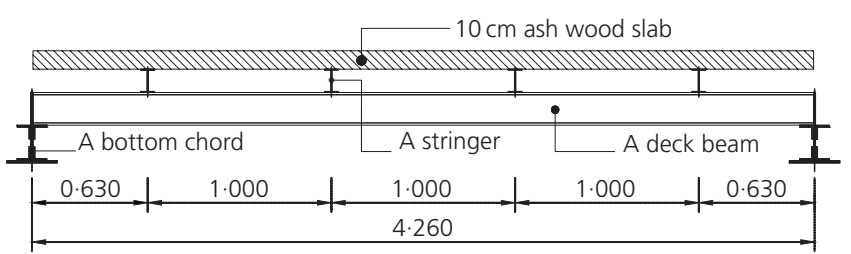

(a)

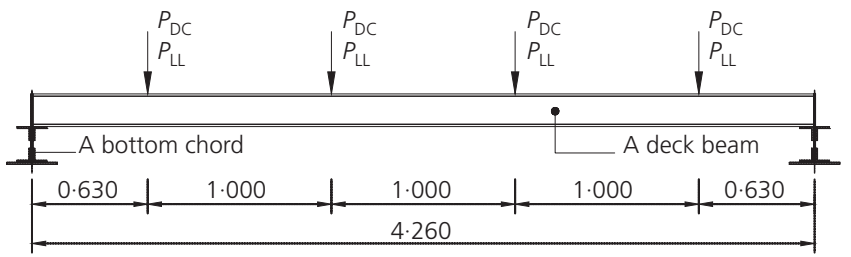

(b)

Figure 8. A new slab design. (a) New slab; (b) loads transfer from the new slab

Figure 7. Removal of deck beam numbers $3-6$ and $45-47$ from north to south sides 

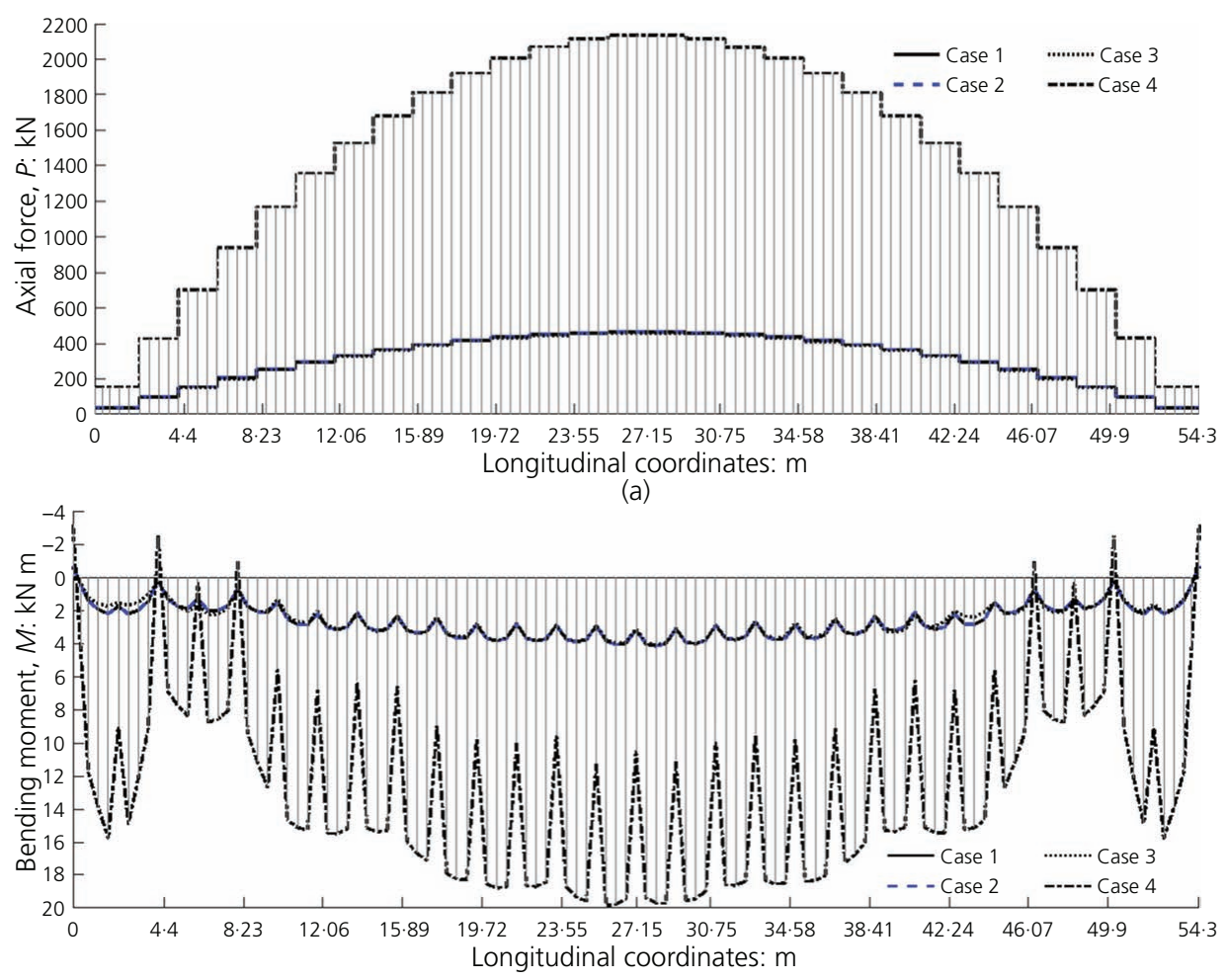

(b)

Figure 9. Axial forces and bending moment in the bottom chord of the bridge: (a) axial forces; (b) bending moment

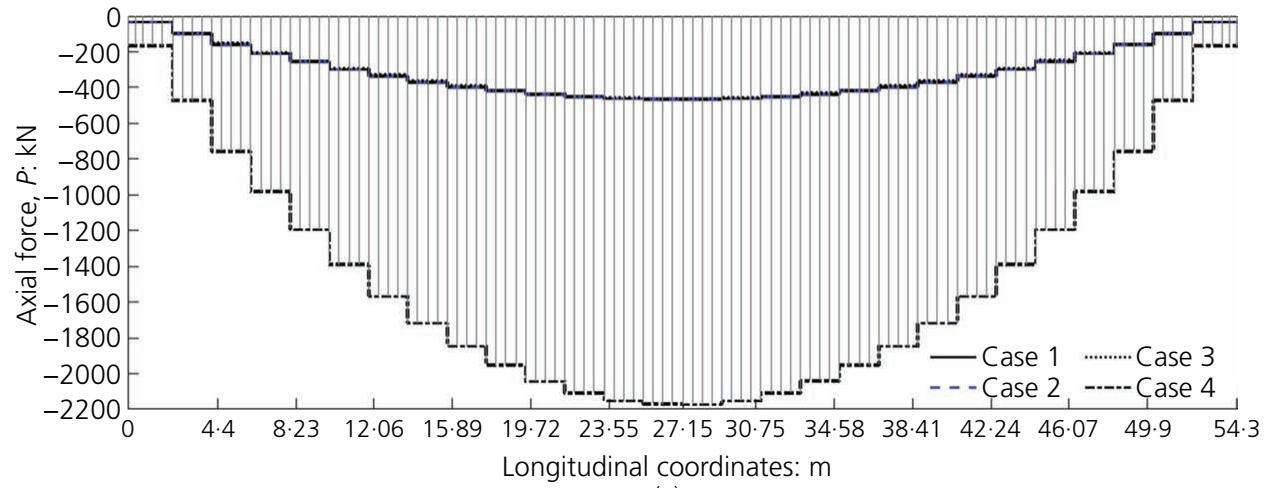

(a)

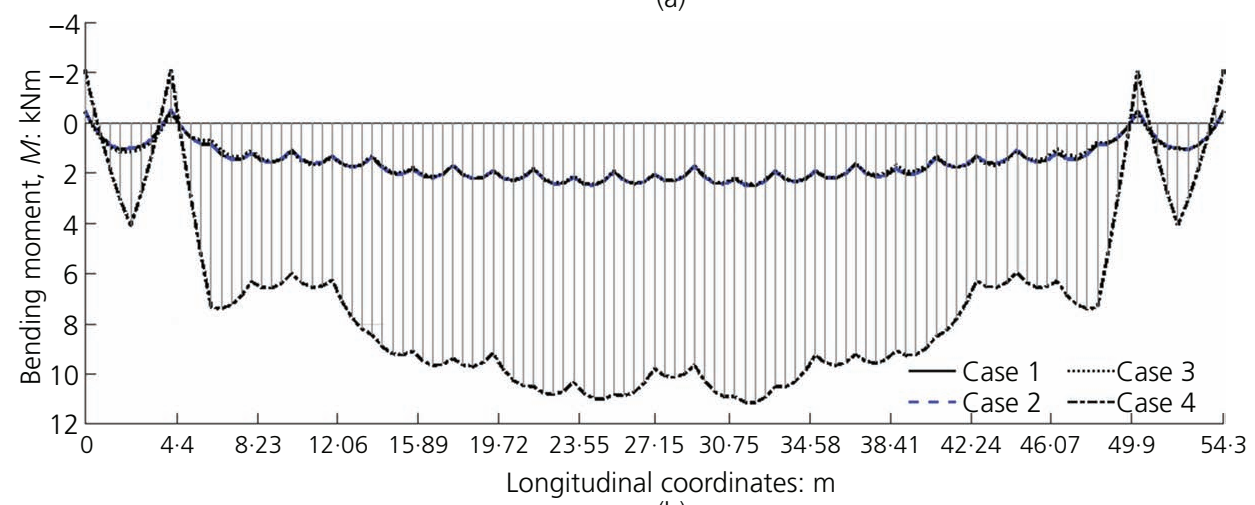

(b)

Figure 10. Axial forces and bending moment in the top chord of the bridge: (a) axial forces; (b) bending moment 
reported in Tables 3 and 4. The results showed that the axial force and bending moment changed slightly in cases $1-3$, whereas the maximum difference of axial force and bending moment found in the bottom chord were, respectively, $5 \mathrm{kN}$ (case 2 against case 3 ) and $0 \cdot 1 \mathrm{kN} \mathrm{m}$ (case 2 against case 3). In case 3 , some deck beams were removed; thus, the internal forces were slightly reduced, because the bridge was subjected only to self-weight. In case 4, when the new slab was installed and the bridge was subjected to a pedestrian load, the internal forces were increased significantly. As an example, the maximum axial force in the bottom chord increased by more than 4.5 times, from $465 \mathrm{kN}$ (case 1) to $2138 \mathrm{kN}$ (case 4), with a similar increase in the bending moment (from $4.2 \mathrm{kN} \mathrm{m}$ in case 1 to $19.8 \mathrm{kN} \mathrm{m}$ in case 4). The same increase also occurred in the primary structural members such as top chords, single and double lattices and end posts. Of special note was the increase in the deck's bending moment from $0.9 \mathrm{kN} \mathrm{m}$ in case 1 to $19.5 \mathrm{kN} \mathrm{m}$ in case 4 , while, the internal forces in the secondary structures (i.e. struts, sways and arches) changed only slightly.

An important issue in checking the capacity of the bridge is to examine the principal stress of the structural members. A summary of the minimum and maximum principal stresses of the structure is provided in Table 5, which were computed from the internal forces at sections of the structural components and the section properties. For cases 1-3, both the compressive and tensile principal stresses of the structural members were under the allowable strength of wrought iron. For example, the maximum compressive principal stress in the top chord was $52 \mathrm{~N} / \mathrm{mm}^{2}$ (nearly $64 \%$ of the allowable compressive

Table 3. Maximum axial forces $(P)$ and bending moments $(M)$ in each type of structural member

\begin{tabular}{|c|c|c|c|c|c|c|c|c|}
\hline \multirow{2}{*}{ Structural member } & \multicolumn{2}{|c|}{ Case 1} & \multicolumn{2}{|c|}{ Case 2} & \multicolumn{2}{|c|}{ Case 3} & \multicolumn{2}{|c|}{ Case 4} \\
\hline & $P: \mathrm{kN}$ & $M: \mathrm{kN} \mathrm{m}$ & $P: \mathrm{kN}$ & $M: \mathrm{kN} \mathrm{m}$ & $P: \mathrm{kN}$ & $M: \mathrm{kN} \mathrm{m}$ & $P: \mathrm{kN}$ & $M: \mathrm{kN} \mathrm{m}$ \\
\hline Bottom chord & 465 & $4 \cdot 2$ & 465 & $4 \cdot 2$ & 460 & $4 \cdot 1$ & 2138 & $19 \cdot 8$ \\
\hline Top chord & -35 & $2 \cdot 5$ & -35 & $2 \cdot 5$ & -33 & $2 \cdot 5$ & -168 & $11 \cdot 1$ \\
\hline Deck beam & 0 & $0 \cdot 0$ & 0 & 0.9 & 0 & 0.9 & 0 & $19 \cdot 5$ \\
\hline Strut & 1 & $0 \cdot 4$ & 1 & 0.4 & 1 & 0.4 & 1 & 0.4 \\
\hline Sway & -0 & $0 \cdot 1$ & 0 & $0 \cdot 1$ & 0 & $0 \cdot 1$ & 0 & $0 \cdot 1$ \\
\hline Single lattice & 47 & $1 \cdot 0$ & 47 & $1 \cdot 0$ & 46 & $1 \cdot 0$ & 225 & $3 \cdot 0$ \\
\hline Double lattice & 1 & $0 \cdot 4$ & 1 & 0.4 & 1 & 0.4 & 11 & 0.8 \\
\hline End post & -34 & $0 \cdot 7$ & -34 & 0.7 & -33 & 0.6 & -155 & $3 \cdot 2$ \\
\hline Arch & -0 & $0 \cdot 3$ & -0 & $0 \cdot 2$ & -0 & $0 \cdot 3$ & -0 & 0.2 \\
\hline
\end{tabular}

Table 4. Minimum axial forces $(P)$ and bending moments $(M)$ in each type of structural member

\begin{tabular}{|c|c|c|c|c|c|c|c|c|}
\hline \multirow{2}{*}{ Structural member } & \multicolumn{2}{|c|}{ Case 1} & \multicolumn{2}{|c|}{ Case 2} & \multicolumn{2}{|c|}{ Case 3} & \multicolumn{2}{|c|}{ Case 4} \\
\hline & $P: \mathrm{kN}$ & $M: \mathrm{kN} \mathrm{m}$ & $P: \mathrm{kN}$ & $M: \mathrm{kN} \mathrm{m}$ & $P: \mathrm{kN}$ & $M: \mathrm{kN} \mathrm{m}$ & $P: \mathrm{kN}$ & $M: \mathrm{kN} \mathrm{m}$ \\
\hline Bottom chord & 35 & -0.7 & 35 & -0.7 & 35 & $-0 \cdot 6$ & 156 & $-3 \cdot 2$ \\
\hline Top chord & -467 & -0.5 & -467 & -0.5 & -462 & -0.5 & -2172 & $-2 \cdot 1$ \\
\hline Deck beam & -0 & -0.5 & -0 & -0.5 & -0 & -0.5 & -0 & $-1 \cdot 5$ \\
\hline Strut & 0 & -0.0 & 0 & -0.0 & 0 & -0.0 & -0 & $-0 \cdot 2$ \\
\hline Sway & -1 & 0.0 & -1 & 0.0 & -1 & 0.0 & -1 & 0.0 \\
\hline Single lattice & -0 & $-0 \cdot 4$ & -0 & $-0 \cdot 4$ & -0 & $-0 \cdot 4$ & 12 & $-0 \cdot 2$ \\
\hline Double lattice & -47 & $-0 \cdot 3$ & -47 & -0.3 & -46 & $-0 \cdot 3$ & -211 & $-0 \cdot 2$ \\
\hline End post & -95 & -0.7 & -95 & -0.7 & -93 & -0.7 & -431 & $-3 \cdot 2$ \\
\hline Arch & -1 & $-0 \cdot 1$ & -1 & $-0 \cdot 1$ & -1 & $-0 \cdot 1$ & -1 & $-0 \cdot 2$ \\
\hline
\end{tabular}

Table 5. Principal stress $\left(S_{11}\right)$ in each type of structural members

\begin{tabular}{|c|c|c|c|c|c|c|c|c|}
\hline \multirow{2}{*}{ Structural member } & \multicolumn{4}{|c|}{ Min $S_{11}: \mathrm{N} / \mathrm{mm}^{2}$} & \multicolumn{4}{|c|}{$\operatorname{Max} S_{11}: \mathrm{N} / \mathrm{mm}^{2}$} \\
\hline & Case 1 & Case 2 & Case 3 & Case 4 & Case 1 & Case 2 & Case 3 & Case 4 \\
\hline Bottom chord & $-1 \cdot 7$ & $-1 \cdot 7$ & $-1 \cdot 2$ & $-17 \cdot 2$ & $36 \cdot 6$ & $36 \cdot 6$ & $36 \cdot 2$ & 168.9 \\
\hline Top chord & $-51 \cdot 8$ & $-51 \cdot 8$ & $-51 \cdot 3$ & -238.5 & $-1 \cdot 0$ & $-1 \cdot 0$ & $-1 \cdot 0$ & $-7 \cdot 4$ \\
\hline Deck beam & $-4 \cdot 0$ & $-4 \cdot 0$ & -4.0 & -88.0 & $4 \cdot 0$ & $4 \cdot 0$ & $4 \cdot 0$ & 88.0 \\
\hline Strut & $-24 \cdot 0$ & $-24 \cdot 0$ & $-24 \cdot 0$ & $-23 \cdot 6$ & $24 \cdot 2$ & $24 \cdot 2$ & $24 \cdot 2$ & $24 \cdot 0$ \\
\hline Sway & $-7 \cdot 5$ & $-7 \cdot 5$ & $-7 \cdot 5$ & $-7 \cdot 6$ & $6 \cdot 3$ & $6 \cdot 3$ & $6 \cdot 3$ & $6 \cdot 3$ \\
\hline Single lattice & $-6 \cdot 0$ & $-6 \cdot 0$ & $-6 \cdot 0$ & $-22 \cdot 3$ & $20 \cdot 5$ & $20 \cdot 5$ & $20 \cdot 3$ & 68.9 \\
\hline Double lattice & $-37 \cdot 6$ & $-37 \cdot 7$ & $-37 \cdot 3$ & $-126 \cdot 7$ & $20 \cdot 9$ & $20 \cdot 9$ & $20 \cdot 8$ & $51 \cdot 3$ \\
\hline End post & $-46 \cdot 6$ & $-49 \cdot 1$ & $-46 \cdot 0$ & $-199 \cdot 2$ & $-4 \cdot 5$ & $-5 \cdot 3$ & -3.9 & $-31 \cdot 5$ \\
\hline Arch & $-12 \cdot 5$ & $-12 \cdot 3$ & $-12 \cdot 5$ & $-12 \cdot 0$ & $12 \cdot 0$ & $11 \cdot 8$ & $12 \cdot 0$ & 11.4 \\
\hline
\end{tabular}

The bold values show the principal stress exceeding the allowable compressive and tensile strength of wrought iron in Table 2 . 
strength of $81 \mathrm{~N} / \mathrm{mm}^{2}$ ) for the top chord in case 1, while the maximum tensile principal stress was $37 \mathrm{~N} / \mathrm{mm}^{2}$ (around $60 \%$ of the allowable compressive strength of $61 \mathrm{~N} / \mathrm{mm}^{2}$ ) for the bottom chord. However, in case 4, the loading on structural members increased significantly and exceeded the allowable strength in terms of the principal stress in the bottom and top chords, deck beam, single lattice, double lattice and end post. Exceedance occurred in the bottom chord (the maximum tensile stress by $169 \mathrm{~N} / \mathrm{mm}^{2}$ ). In the top chord, the maximum compressive stress was $239 \mathrm{~N} / \mathrm{mm}^{2}$. As such, the bridge structure would not satisfy modern strength requirements, if the slab was rebuilt and subjected to modern pedestrian loads, even in an undamaged state. As such, the study demonstrated that with its current condition, the slab most definitely cannot be rebuilt to modern standards to serve the community without significant structural retrofit.

In terms of deformation analysis, the bridge's deflections were described as the vertical displacement of the bottom chord (Figure 11). This was examined by comparing the allowable deflection $L / 500$ ( $L=54.3 \mathrm{~m}$ is the span length) according to AASHTO (2012). The maximum deflections from cases 1-3 were mostly the same, with the maximum deflections less than $30 \mathrm{~mm}$. In case 4 with the new slab, deflection increased to $42.3 \mathrm{~mm}$ corresponding to $1 / 1285 \mathrm{~L}$ under the DL and a further $67 \cdot 1 \mathrm{~mm}$ with the addition of the LL, which was slightly larger than the maximum allowable deflection of $108.6 \mathrm{~mm}$. This demonstrates that the bridge in an undamaged state with a new slab subjected to modern pedestrian loads would not satisfy the deformation limitation requirements and would exceed the principal stress limit, which raises the question of the appropriateness of applying modern concepts to historic structures. In this case, given the extreme deterioration of many of the sections, the bridge is clearly at risk with respect to its continued existence under its current self-weight.

\section{Discussion}

In the absence of site-specific documentation, period building standards and codes, this project was heavily guided by assumptions and educated judgements, as must typically happen in the assessment of historic bridges (Fernandez, 2017). The fabric of the bridge was previously recorded by the Department of Arts, Heritage and the Gaeltacht (2012) as cast iron of unknown specification. However, during this study, the authors found reason to believe that the structure was composed of wrought iron. This was based on the visual survey conducted, in which the dimensional characteristics of cast iron, wrought iron and steel as listed in the report by Ciria (1994) were compared. Specifically, typical features of the physical elements, such as the small, equal flange I deck beam sections and the small plate sections riveted together with rounded corners to form the chords, were not in agreement with characteristic shapes of cast-iron elements. Furthermore, according to an initial numerical analysis (not reported herein) based on the originally reported cast-iron designation of the bridge and standard properties for that material, most of the bridge's structural members had principal stresses exceeding the allowable stress when the undamaged version of the bridge was subjected to its self-weight. Those numerical results did not coincide with the visual inspection. As such, the model was rerun using typical material attributes of historic wrought iron sections and affiliated material properties.

Following the reexamination of the results using the characteristics of wrought iron, the scanned model reflected the visual observations with respect to extant cross-section shapes and in situ performance. Since access to the structure was restricted and the line of sight was limited, the scan data for the bridge were acquired from only two positions but provided information beyond what was available by way of direct visual inspection in terms of element lengths and cross-sectional areas. This demonstrated the inherent usefulness of TLS for data collection for creating a numerical model. The ability to do such documentation in only an hour also argues for the superiority of using TLS in terms of both data accuracy, cost and schedule compared to traditional means or even those from an unmanned vehicle. For example, unmanned aerial vehicle (UAV)-based

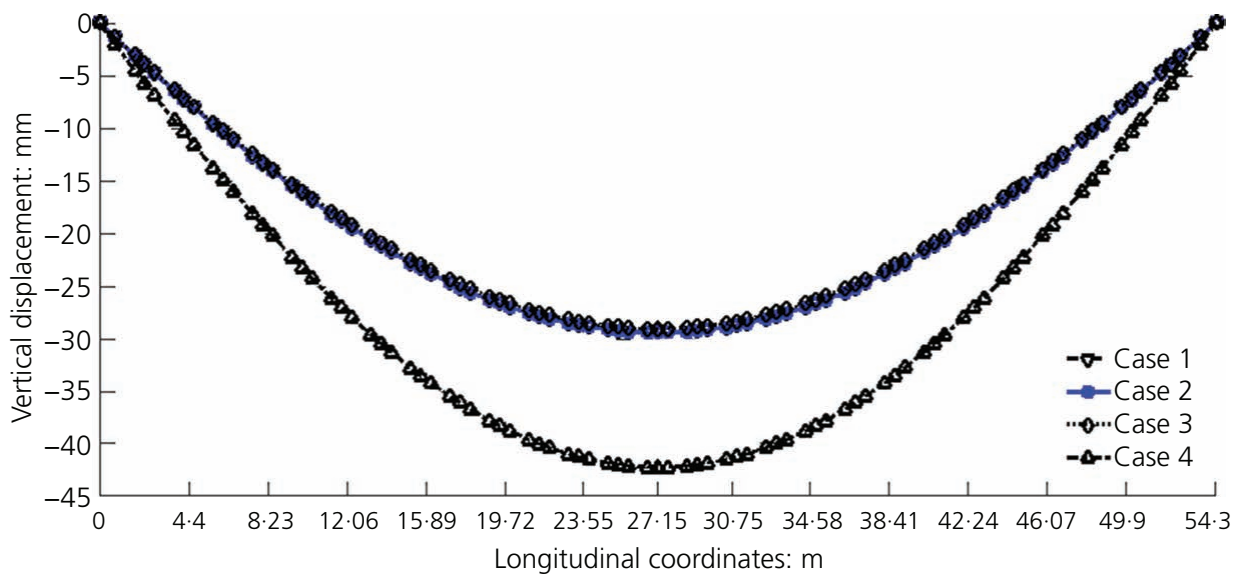

Figure 11. Deflection of the bottom chords due to dead loads 
imagery, which is a prominent method for bridge inspection, has an average error of about $15 \mathrm{~mm}$ (Palmer et al., 2015) and requires extensive processing to generate a point cloud from the raw imagery. With such an error budget, deploying image-based point cloud for reconstructing $3 \mathrm{D}$ models of metal members is problematic (Laefer and Truong-Hong, 2017). Instead, the crosssections generated herein had an average difference between the estimated and recorded library sections of only $285.9 \mathrm{~mm}^{2}$ (std = $314 \cdot 1 \mathrm{~mm}^{2}$ ). Importantly, however, as with all line-of-sight technologies, mixed pixels, registration errors and missing data may cause section misidentification and increase errors in determining the overall dimensions of the bridge.

Finally, without the TLS data, remotely estimating the dimensions of the members safely, cost effectively and with reasonable accuracy would have been extremely difficult and time consuming. That said, the data accuracy and level of detail collected could be improved by the following actions: (a) conducting the scan when all foliage is off the trees; (b) increasing the number of scans conducted (where possible); (c) widening the range of scan locations (where possible); (d) scanning the structure from all faces including from the river and the air (e.g. using UAV-based laser scanning or TLS integrated with a boat); and (e) increasing the scanning resolution.

As reported in Tables 5 and 6, when the actual cross-section without damage and wrought iron material properties were used in the model and the bridge was subjected to self-weight loading, as in case 1, the highest principal stresses generated from the numerical modelling $\left(52 \mathrm{~N} / \mathrm{mm}^{2}\right.$ in compression and $37 \mathrm{~N} / \mathrm{mm}^{2}$ in tension) were smaller than the allowable stress. The maximum displacement under self-weight found at midspan was $29.431 \mathrm{~mm}$. However, the as-designed structure was not representative of the current bridge. Visual assessment confirmed excessive material damage from corrosion (Figure 6), which can cause the stiffness reduction of elements such as the deck. Two additional numerical analyses (cases 2 and 3) were conducted to consider potential element deficiencies: either decay or loss of functionality. Those results showed that neither the stiffness reduction of the deck beams nor the removal of several deck beams negatively impacted the primary structures (e.g. bottom and top chords and lattices) in terms of the principal stress and deflection. However, when considering the recommendation by Gagg and Lewis (2011) and Beal (2011) that ageing and material degradation could further reduce the existing structure's ultimate strength by half, this would have limited the compressive and tensile strength of the wrought iron to 41.5 and $30.5 \mathrm{~N} / \mathrm{mm}^{2}$, respectively. In that case, the principal stresses in both the bottom and top chords and the end post would exceed the reduced allowable strength. For example, in case 2, the compressive principal stress in the top chord and end post were, respectively, 52 and $49 \mathrm{~N} / \mathrm{mm}^{2}$ with no safety factor incorporated into this value.

To consider reopening the bridge to serve the local community, a new wooden slab (and additional LL) would be needed. Case 4 considered this in the ideal scenario of no degradation with respect to structural members but with modern pedestrian loading requirements. In that case, the numerical results showed that in the primary members (e.g. bottom and top chords, deck beam and lattices), loading demands would have increased by nearly 3 times for the compressive stress $\left(239 \mathrm{~N} / \mathrm{mm}^{2}\right.$ against $81 \mathrm{~N} / \mathrm{mm}^{2}$ in a top chord) and $2 \cdot 7$ times for the tensile stress $\left(169 \mathrm{~N} / \mathrm{m}^{2}\right.$ against $61 \mathrm{~N} /$ $\mathrm{mm}^{2}$ in a bottom chord). In this case, the maximum principal stress in most structural components exceeded the strength of the wrought iron, but the principal stresses were mainly caused by LL. For example, in the bottom chord, the maximum tensile principal stresses consisted of $52 \mathrm{~N} / \mathrm{mm}^{2}$ from DL and $116 \mathrm{~N} / \mathrm{mm}^{2}$ from LL. However, the principal stress due to DL is around $86 \%$ of the tensile strength $\left(52 \mathrm{~N} / \mathrm{mm}^{2}\right.$ against $\left.61 \mathrm{~N} / \mathrm{mm}^{2}\right)$. Thus, reopening the bridge to serve the community cannot be safely undertaken at this time under current codes.

\section{Conclusions}

This investigation highlighted the beneficial role of terrestrial laser scanning technology in documenting and assessing a historic wrought iron bridge, particularly where the geometry is otherwise unrecorded. In the presented case study of the Guinness Bridge, geometries of the bridge components were acquired from only two positions (and both from the same abutment). However, this was sufficient for identifying cross-sections of all components and the overall dimensions of the bridge to create a numerical model from the resulting point cloud. The success of the proposed method proved that TLS can surpass other common techniques (e.g. UAV-based images) for acquiring geometric models of the bridge in terms of quantity and quality of the data points and timing. However, with restricted access to the bridge allowing only two scanning positions, the acquired data points may not record the deficiencies of components farther from the scanner, which limits the reliability of the modelling.

The geometries and cross-sections based on the TLS data agreed with a published historic record, thereby confirming the suitability

Table 6. Summary table of model performance

\begin{tabular}{llcccccc}
\multirow{2}{*}{ Structural scenario } & \multicolumn{2}{c}{ Load } & & \multicolumn{2}{c}{ Material capacity $\mathbf{1 0 0 \%}$} & & \multicolumn{2}{c}{ Material capacity $\mathbf{5 0 \%}$} \\
\cline { 2 - 5 } & DC & LL & Principal stress & Deflection & & Principal stress & Deflection \\
\hline Case 1 & Yes & None & OK & N/A & & Exceeded & N/A \\
Case 2 & Yes & None & OK & N/A & & Exceeded & N/A \\
Case 3 & Yes & None & OK & N/A & & Exceeded & N/A \\
Case 4 & Yes & Yes & Exceeded & Yes & & Exceeded & Exceeded
\end{tabular}


of the technology and the authors' conclusion that the structural material was wrought iron, as opposed to the officially recorded cast-iron designation. A successful methodology for generating a 3D model can be applied to other similar structures. Subsequent simple modelling showed that the bridge, in its current geometry and assuming original material properties, is likely to be able to satisfy both strength and serviceability requirements under selfweight without its deck, thereby demonstrating that further the intervention and inspection of the bridge can be done safely without concern for progressive collapse. However, in terms of the possibility of reopening the bridge for community service, the analysis concluded that the stress demands in the primary structures greatly exceeded the allowable strength.

To adequately assess the structure, material testing using noninvasive methods is needed, along with detailed modelling of each damaged member. Irrespective of the limitations of this study and the ultimate fate of the bridge, TLS documentation can provide a detailed record of the structure for future assessments both in terms of cross-sectional geometry and overall dimensions for numerical modelling.

\section{Acknowledgements}

This work was sponsored with funding from the EU's grant ERC StG 2012-307836-RETURN. The authors are grateful to $\mathrm{Mr}$ Donal Lennon for his assistance in data acquisition.

\section{REFERENCES}

AASHTO (American Association of State Highway and Transportation Officials) (2012) AASHTO LRFD 2012 Bridge Design Specifications, 6th edn. Aashto, Washington, DC, USA.

Al-Neshawy F, Piironen J, Peltola S et al. (2010) Measuring the bowing of marble panels in building facades using terrestrial laser scanning technology. Journal of Information Technology in Construction 15(10): 64-74.

Armesto-González J, Riveiro-Rodríguez B, González-Aguilera D and Rivas-Brea MT (2010) Terrestrial laser scanning intensity data applied to damage detection for historical buildings. Journal of Archaeological Science 37(12): 3037-3047, http://dx.doi.org/10.1016/j.jas.2010.06.031.

Bates W (1991) Historical Structural Steelwork Handbook. British Constructional Steelwork Association, London, UK.

Beal AN (2011) A history of the safety factors. The Structural Engineer 89(20): 20-26.

Camarda M, Guarnieri A, Milan N and Vettore A (2010) Health monitoring of complex structure using TLS and photogrammetry. International Archives of Photogrammetry, Remote Sensing and Spatial Information Sciences 38(5): 125-130.

Castellazzi G, D'Altri AM, Bitelli G, Selvaggi I and Lambertini A (2015) From laser scanning to finite element analysis of complex buildings by using a semi-automatic procedure. Sensors 15(8): 18360-18380, http:// dx.doi.org/10.3390/s150818360.

Ciria (Construction Industry Research and Information Association) (1994) Structural Renovation of Traditional Buildings, Construction Industry Research and Information Association. CIRIA, London, UK, Report 111.

CSI (Computers \& Structures Inc.) (2014) SAP2000 Version 17. CSI, New York, NY, USA.

Department of Arts Heritage and the Gaeltacht (2012) National Inventory of Architectural Heritage. Department of Arts, Heritage and the Gaeltacht, Dublin, Ireland, Reg No. 11362030. See http://www. buildingsofireland.ie/niah/search.jsp?type=record\&county $=$ FI\&regno= 11362030 (accessed 22/08/2016).

Doran D and Cather B (2013) Construction Materials Reference Book. Routledge, London, UK.

Fereshteh H (2012) Digital technologies in documenting the cultural heritage review of laser scanners. In Proceedings of the 8th International Conference on Structural Analysis: Structural Analysis of Historic Construction: Preserving Safety and Significance (Jasienko J (ed.)). CRC Press, Boca Raton, FL, USA, pp. 2385-2389.

Fernandez S (2017) Engineer's approach to conservation. Proceedings of the Institution of Civil Engineers - Engineering History and Heritage 170(2): 53-66, https://doi.org/10.1680/jenhh.16.00018.

Friedman D (2010) Historical Building Construction: Design, Materials, and Technology. WW Norton \& Company, New York, USA.

Gagg CR and Lewis PR (2011) The rise and fall of cast iron in victorian structures - a case study review. Engineering Failure Analysis 18(8): 1963-1980, http://dx.doi.org/10.1016/j.engfailanal.2011.07.013.

Heath J and Miller J (2014) A history of structural defects and repairs, the Iron Bridge, Shropshire. Proceedings of the First Conference of the Construction History Society 2015, 16 March, Cambridge, UK, pp. 201-208.

Hinks T, Carr H, Truong-Hong L and Laefer DF (2013) Point cloud data conversion into solid models via point-based voxelization. Journal of Surveying Engineering 139(2): 72-83, http://dx.doi.org/10.1061/ (ASCE)SU.1943-5428.0000097.

Icomos (International Council on Monuments and Sites) (2003) ICOMOS Charter - Principles for the Analysis, Conservation and Structural Restoration of Architectural Heritage. Icomos, Charenton-le-Pont, France. See http://www.icomos.org/charters/structures_e.pdf (accessed 24/08/2017).

Laefer DF and Truong-Hong L (2017) Toward automatic generation of 3D steel structures for building information modelling. Automation in Construction 74: 66-77, http://dx.doi.org.10/1016/j.autcon.2016.11. 011.

Leica Geosystems AG (2014) Leica Cyclone V.9.1. Leica Geosystems AG, Heerbrugg, Switzerland.

Leica Geosystems AG (2016) Leica CloudWorx for AutoCAD. Leica Geosystems AG, Heerbrugg, Switzerland.

Miller J (2015) The Iron Bridge: desk study and engineering assessment. Proceedings of the Institution of Civil Engineers - Engineering History and Heritage 168(4): 177-185, https://doi.org/10.1680/jenhh. 15.00018 .

Olsen MJ, Kuester F, Chang BJ and Hutchinson TC (2010) Terrestrial laser scanning-based structural damage assessment. Journal of Computing in Civil Engineering 24(3): 264-272, http://dx.doi.org/10.1061/ (ASCE)CP.1943-5487.0000028.

Palmer L, Franke K, Abraham Martin R, Sines B, Rollins K and Hedengren J (2015) Application and accuracy of structure from motion computer vision models with fullsScale geotechnical field tests. IFCEE 2015: 2432-2441, http://dx.doi.org/10.1061/9780784479087.225.

Phares BM, Washer GA, Rolander DD, Graybeal BA and Moore M (2004) Routine highway bridge inspection condition documentation accuracy and reliability. Journal of Bridge Engineering 9(4): 403-413, http:// dx.doi.org/10.1061/(ASCE)1084-0702(2004)9:4(403).

Rattan SS (2011) Strength of Materials, 2nd edn. Tata McGraw-Hill Education Pvt. Ltd, New Delhi, Delhi, India.

Truong-Hong L and Laefer DF (2014) Application of terrestrial laser scanner in bridge inspection: review and an opportunity. In IABSE Symposium Report, IABSE Madrid Symposium: Engineering for Progress, Nature and People. International Association for Bridge and Structural Engineering, Zurich, Switzerland, pp. 2713-2720.

Truong-Hong L and Laefer DF (2015a) Documentation of bridges by terrestrial laser scanner. In IABSE Symposium Report, IABSE 
Engineering History and Heritage

Volume 171 Issue EH2
Laser scan-based structural assessment of wrought iron bridges: Guinness Bridge,

Ireland

Gyetvai, Truong-Hong and Laefer
Conference Geneva 2015: Structural Engineering: Providing Solutions to Global Challenges. International Association for Bridge and Structural Engineering, Zurich, Switzerland, pp. 1-8.

Truong-Hong $\mathrm{L}$ and Laefer DF (2015b) A semi-automatic member detection for metal bridges. In IABSE Symposium Report, IABSE Conference Nara, 2015: Elegance in Structures. International Association for Bridge and Structural Engineering, Zurich, Switzerland, pp. 1-7.
Truong-Hong L, Gharibi H, Garg H and Lennon D (2014) Equipment considerations for terrestrial laser scanning for civil engineering in urban areas. Journal of Scientific Research and Reports 3(15): 2002-2014, http://dx.doi.org/10.9734/JSRR/2014/7482.

Zhu Z, German S and Brilakis I (2010) Detection of large-scale concrete columns for automated bridge inspection. Automation in Construction 19(8): 1047-1055, http://dx.doi.org/j.autcon.2010.07.016.

\section{How can you contribute?}

To discuss this paper, please email up to 500 words to the editor at journals@ice.org.uk. Your contribution will be forwarded to the author(s) for a reply and, if considered appropriate by the editorial board, it will be published as discussion in a future issue of the journal.

Proceedings journals rely entirely on contributions from the civil engineering profession (and allied disciplines). Information about how to submit your paper online is available at www.icevirtuallibrary.com/page/authors, where you will also find detailed author guidelines. 